\title{
Knowledge politics in the smart city: A case study of strategic urban planning in Cambridge, UK
}

\author{
Timea Nochta ${ }^{1, *}$ (D), Noura Wahby ${ }^{2}$ and Jennifer M. Schooling ${ }^{1}$ \\ ${ }^{1}$ Centre for Smart Infrastructure and Construction, University of Cambridge, Cambridge, United Kingdom \\ ${ }^{2}$ Department of Public Policy and Administration, The American University in Cairo, Cairo, Egypt \\ *Corresponding author. E-mail: tn328@cam.ac.uk
}

Received: 05 May 2021; Revised: 23 September 2021; Accepted: 02 October 2021

Key words: city science; knowledge production; situated knowledge; smart city; urban planning

Abbreviations: CAM, Cambridgeshire Autonomous Metro; CPCA, Cambridgeshire and Peterborough Combined Authority;
CSRM, Cambridge Sub Regional Model; GCP, Greater Cambridge Partnership; LLF, Local Liaison Forum

\begin{abstract}
This paper highlights the need and opportunities for constructively combining different types of (analogue and datadriven) knowledges in evidence-informed policy decision-making in future smart cities. Problematizing the assumed universality and objectivity of data-driven knowledge, we call attention to notions of "positionality" and "situatedness" in knowledge production relating to the urban present and possible futures. In order to illustrate our arguments, we draw on a case study of strategic urban (spatial) planning in the Cambridge city region in the United Kingdom. Tracing diverse knowledge production processes, including top-down data-driven knowledges derived from urban modeling, and bottom-up analogue community-based knowledges, allows us to identify locationally specific knowledge politics around evidence for policy. The findings highlight how evidence-informed urban policy can benefit from political processes of competition, contestation, negotiation, and complementarity that arise from interactions between diverse "digital" and "analogue" knowledges. We argue that studying such processes can help in assembling a more multifaceted, diverse and inclusive knowledge-base on which to base policy decisions, as well as to raise awareness and improve active participation in the ongoing "smartification" of cities.
\end{abstract}

\section{Policy Significance Statement}

Articulating the value of smart city development necessitates a deeper understanding of how knowledge about the city derived from digital data, and the "new science of cities", can contribute to improving evidence-informed urban policy and services. This paper argues that the role of this data-driven knowledge should be considered as part of a multifaceted evidence-base to inform policy decisions. With the tendency of data-driven knowledge to claim monopoly over knowing and understanding the city, incorporating other forms of knowledge, for example, diverse analogue community knowledges, requires concerted effort from city leaders, practitioners, and researchers. 


\section{Introduction}

In this paper, we highlight the need and opportunities for constructively combining different types of knowledge in evidence-informed policy decision-making in future smart cities. Problematizing the assumed universality and objectivity of data-driven knowledge(s), we call attention to notions of "positionality" and "situatedness" in knowledge production relating to the urban present and possible futures. We argue that evidence-informed urban policy can, in fact, benefit from political processes of competition, contestation, negotiation, and complementarity that arise from interactions between diverse "digital" and "analogue" knowledges. Studying such interactions can therefore help not only in moving toward a more multifaceted, diverse and inclusive knowledge-base on which to base policy decisions, but also to raise awareness and improve active participation in the ongoing "smartification" of cities.

We aim to show that "smartification" in urban policy decision-making is as much —if not more-about embedding data-driven knowledge(s) in a broader evidence-base as it is about improving their quality and accuracy in a narrow techno-scientific sense. This is important because much of the (academic and commercial) research on implementing digital technologies in urban spaces focuses on collecting better quality, more accurate data more (cost-)efficiently, processing and analyzing it an automated manner, and exploring options to automate various decision-making processes from traffic management to policing and approving planning applications.

Our focus is therefore on a particular aspect of smart city development that aims at leveraging data and digital technologies to develop fine-grained information about the functioning of city systems. This, in turn, is used to derive data-driven knowledge and evidence for governing cities. To develop a more nuanced understanding of the implications of this increasing volume of data-driven knowledge in a realworld setting, the arguments put forward in this paper are illustrated through the case of knowledge production and politics in strategic urban planning in the Cambridge city region in the United Kingdom.

We recognize that the 'smart city' concept remains ill-defined, used in diverse contexts for different purposes, and may mean different things to different stakeholders such as policymakers, researchers, industry, technology providers, and citizens (Kitchin, 2014; Mora et al., 2019; Zuzul, 2019; Jacobs et al., 2020). Consequently, the discussion presented here with a focus on policy evidence and knowledge production, may be more relevant in certain geographical locations, policy domains, and research disciplines than others. Nevertheless, our aspiration is that it will inspire further research into exploring the diversity of smartification trajectories and the social-political contexts which give rise to them, and the knowledges and knowledge politics that shape them (cf. de Hoop et al., 2018; Chang et al., 2021).

The paper is structured as follows. Section 2 links the concepts of "evidence" and "knowledge" in the context of the smartification of urban governance. Section 3 introduces the empirical case of "knowledge politics" in the Cambridge city region (UK), giving a short overview of the provision and use of "datadriven" and "analogue" knowledges as evidence in strategic urban planning. Conclusions and recommendations for further research for improving evidence-informed policy decision-making in future smart cities are then presented in Section 4.

\section{Knowledges and Evidence in Smart Urban Planning}

While the smart city agenda is relatively new, the drive to "rationalize" public policy and services has a longer history. For instance, public sector reforms starting from the 1970s, termed collectively as new public management (NPM), contributed to creating an emphasis on "evidence" for policy and service delivery (Pollitt and Bouckaert, 2011). Today, a large body of literature exists on "evidence-based policy" (EPB) (Wastell, 2006; Head, 2008; Cairney, 2016; Parkhurst, 2017). Evidence in this context is derived from relevant scientific information to construct policy advice or evaluation, using various scientific tools and instruments (Turnpenny et al., 2015). Tools and instruments are used for example to collect data (e.g., surveys and sensors); frame and structure the policy problem in question (e.g., mapping tools, expert reports, stakeholder workshops, opinion polls, and decision theaters); define objectives (e.g., scenario analyses); and to produce assessment and recommendations (e.g., cost-benefit analyses, economic forecasting, computerized models, and simulations). 
According to the NPM-inspired managerial view, EPB contributes to improved efficiency, effectiveness, transparency, and legitimacy and increased civic trust in decision-makers. However, as Head (2008, p. 4) writes, with the increasingly dominant perception of policy problems as "complex, interlinked and cross-cutting," the appropriateness of basing policy decisions predominantly on technical expertise "has become subject to intense debate and uncertainty." As a result, moving beyond "evidence-based" claims, evidence-informed policy approaches started emerging with more focus on diversity where "disparate bodies of knowledge become multiple sets of evidence that inform and influence policy rather than determine it" (Head, 2008, p. 4). These approaches still acknowledge the utility of scientific evidence in improving policymaking practice, but also assert that it must be embedded into a wider context because much of the policy process is about reconciling various value perspectives. Methods suggested to develop a diverse evidence base that takes context into account include different forms of engagement with communities and different experts and stakeholders and sectors (Head, 2010).

The smart city agenda thus emerged at a time (1990s) when policy scholars were already debating the potential incompleteness of scientific knowledge(s) in dealing with complex policy problems and the importance of multiple sets of evidence on which to base decisions. Nevertheless, its core focus remained for a long time on how digital technologies (ICTs), and the associated data-driven knowledge(s), can provide the means to tackle urban challenges. In response, a large body of critical literature emerged that considers the ongoing smartification of cities as part of periodic historical waves of techno-scientific interventions into the city that most often fail to achieve the promised utopian outcomes (Söderström et al., 2014; Leszczynski, 2016; Marvin and Luque-Ayala, 2017; Jacobs et al., 2020).

Despite this growing research evidence on the drawbacks and shortcomings of smart city initiatives, leading tech companies (such as IBM, Cisco, Siemens, ABB, or Hitachi) continue to promote technologyled "solutions" and a simplistic double-helix model of participation that includes only tech companies (as solution providers) and local governments (as clients) (Mora et al., 2019). As such they envision a governance model in which urban knowledge production is captured by technology providers with a commercial interest and outside the reach of democratic scrutiny (de Hoop et al., 2018).

Much in line with policy scholars' interest in new, more collaborative and participative models of knowledge production for evidence-informed policy, research emerging from innovation studies also calls for broader inclusion in smartification processes in a quadruple-helix model where "different urban stakeholders (public, private, and civic) engage in coalitions and innovate together" (van Winden and van den Buuse, 2017, p. 68). Mora et al. (2019, p. 72) highlight that such engagement and participatory processes are critical for providing the necessary "intellectual capital" for successful smartification. Although recognizing the importance of broader participation, many commentators draw attention to the difficulties inherent in making participation and collaboration work well (cf. Zuzul, 2019). In particular, the active involvement of diverse urban civil society groups, communities and individual citizens appears challenging (de Hoop et al., 2018; Khan et al., 2020; Mancebo, 2020; Panori et al., 2020).

So whilst citizen engagement, open innovation and policy co-creation are considered key components of "smart" urban governance (Meijer and Bolívar, 2016), it remains unclear how diverse "digital" and "analogue" knowledges could or should be combined constructively to improve decision-making processes and outcomes in aspiring smart cities (cf. Smith and Martín, 2021). This is problematic because, in the context of the ongoing smartification of cities, data-driven "evidence" exhibits a tendency to claim monopoly (or at least superiority) over knowing and understanding the urban at the expense of othersfor example, professional experience or diverse local community perspectives (Kitchin, 2016). Nonetheless, as cities digitalize to form new types of rules and disciplines, alternative - contesting and/or complementary - knowledges soon come to the surface (de Hoop et al., 2018). Scholars studying the Global South have already recognized that these community-based knowledges can, at times, become a powerful tool to mediate the success, failure and form of technological interventions into the city (Bhan, 2016; Björkman and Harris, 2018; Gopakumar, 2020).

In order to deepen our understanding of these unfolding processes of "knowledge politics,"we propose that notions of "positionality" and "situatedness" can help make sense of knowledge production in and 
about the smart city (Merrifield, 1995; Haraway, 1988; Leino and Peltomaa, 2012). Such perspectives contend that knowledge is inherently contextual, partial, located, and relational:

... knowledge is always embedded in a particular time and space; it doesn't see everything from nowhere but rather sees somethings from somewhere (Merrifield, 1995, p. 50).

In this understanding, diverse "data-driven" and "analogue" knowledges may exist that can all be viewed as "situated" in the sense that they are "produced in specific circumstances and that those circumstances shape [them] in some way" (Rose, 1997, p. 305).

In the context of urban smartification, it could be tempting to consider data-driven knowledges as exclusively top-down and hegemonic, and analogue knowledges as bottom-up community activism. However, data-driven knowledges can be produced through bottom-up initiatives and grassroots movements as various citizen sensing initiatives demonstrate (Gabrys, 2014; de Hoop et al., 2018; Zandbergen and Uitermark, 2020) and analogue (nondigitized) knowledges are inherently part of top-down decisionmaking processes. For example, Head (2008), in his discussion on EPB, highlights the importance of political and practical implementation knowledges alongside scientific evidence. Jin (forthcoming) argues that, in urban planning, beyond data and models, "big decisions on cities' future plans and investments still rest, like they always have done, on intuition, instincts and inspiring anecdotes."

In the following, we zoom into processes of knowledge production in strategic urban planning in the Cambridge city region in the United Kingdom. The discussion is aimed at illustrating how might this situated knowledge framing contribute to a more nuanced understanding of smartification processes in different places. It will also explore the potential for assembling multifaceted evidence bases that draw on diverse sources of "data-driven" and "analogue" knowledges and highlight potential benefits for urban development. As such, we recognize that despite the "enduring influence of techno-politics," there is both a need and an opportunity to develop "alternative pathways of urban development that can selectively involve new technologies" (Karvonen, 2020, p. 421). We argue that finding ways to constructively combine different types of knowledge can help achieve this aim, redirecting smartification processes toward creating more sustainable and equitable urban futures (Nochta et al., 2019d; Du et al., 2021; Mora et al., 2021).

\section{An Illustrative Case: Strategic Urban Planning in Cambridge}

To start unpacking the knowledge politics pertinent to the smartification of cities, we looked at the ways in which different types of knowledge (data-driven and analogue) influence decision-making in strategic urban planning in Cambridge, UK (see also Nochta et al., 2019b). Cambridge is a growing city with high ambitions in terms of economic and spatial development targets, but constrained in terms of options to deliver on them. For example, both Cambridgeshire County Council and Cambridge City Council declared climate emergencies and expressed strong commitment to achieving the national government's net-zero carbon target by 2050. At the same time, the Greater Cambridge Partnership (GCP) is tasked with delivering over 30000 new homes and 44000 new jobs, with a projected $25.9 \%$ population growth in the Cambridge city region in the next decade (www.greatercambridge.org.uk). Data and smart (digital) solutions are seen as essential to accommodate the projected growth and at the same time also deliver on sustainability targets by many powerful stakeholders (Nochta et al., 2021). However, it remains to be seen whether the associated digitally enabled urban planning and management processes and initiatives will provide space for developing a multifaceted knowledge-base for evidence in urban policy that involves diverse data-driven and analogue knowledges about the city region.

In the following sections, we investigate the ways in which digitalization and other streams of knowledge production interact in the policy domain of strategic urban planning. As this is an illustrative case, the analysis does not strive to be exhaustive, but rather aims at highlighting interesting and/or surprising findings and questions for future research. Following the strand of research that calls for more attention to the active involvement of diverse urban civil society groups, communities and individual 
citizens in smartification, we focus on data-driven knowledge as produced through urban data collection and modeling exercises (largely top-down) and analogue community knowledges (bottom-up), and the ways in which these interact in strategic urban planning.

The case description draws on both primary and secondary data. Primary data have been collected over a period of 2 years between 2019 and 2020, involving two rounds of data collection resulting in a total of 37 interviews. Respondents included key stakeholders with diverse backgrounds and roles in local policy decision-making around issues relating to two key aspects of urban planning, namely land-use and transport. Selected respondents included public sector officers, councilors and other political figures, researchers, large employers, self-employed professionals, residents' associations, and city-wide campaign groups. The data collected from primary sources have been complemented with information gathered from national and local policy documents, technical and consultancy reports and outputs of previous research.

\subsection{Top-down policy decision-making and data-driven knowledges}

Data about the city in Cambridge is being collected and used in decision-making in many different ways by various organizations. Available data sets relevant to strategic planning include, for example, the UK Census and other survey data on Business and Employment and Labor Force from national level data collection. Locally coordinated data generation activities target issues relevant to local development targets, such as demographic changes, air quality, housing, and employment (see https:// cambridgeshireinsight.org.uk/). In addition to these more traditional data collection methods, a range of new data are becoming available through for example the monitoring of public transport and journey times (https://smartcambridge.org/transport/map/) and using automatic number plate recognition (ANPR) technology (Wan et al., 2021). In strategic urban planning, these data are often used to support digital modeling. Such digital models of cities aim at understanding, explaining, and simulating the functioning of urban systems and provide information on the impact of spatial development plans (Wilson, 1998).

Pioneering research into modeling the interactions among urban land use, built form, business and consumer activities and transport services at the University's Martin Centre for Architectural and Urban Studies (www.martincentre.arct.cam.ac.uk/research/citiesandtransport) inspired policymakers in Cambridge to make use of this type of evidence from the 1960s (Hunt et al., 2005). The role of data and models has since been strengthened in subsequent decades in a broader context of an ever-increasing demand for EPB. Various digital simulation models have been developed and applied in Cambridge, for example, through programmes such as the Cambridge Futures (MEPLAN; Echenique, 2005) and the Cambridgeshire and Peterborough Independent Economic Review (LUISA; Cambridgeshire and Peterborough Independent Economic Commission, 2018). These programmes covered various issues relating to balancing the continued growth of the city region and its economy, and the associated impact (e.g., on land use changes, housing transportation, and air quality).

Despite the academic roots of urban modeling, consultants have become increasingly important in producing modeling and data-driven evidence for policymaking over the last two decades. For example, the Local Transport Plans are supported by the Cambridge Sub Regional Model (CSRM) managed and operated by consultants WSP and Atkins on behalf of Cambridgeshire County Council. CSRM is a strategic model of land use and transport behavior in four local authority districts (comprising Cambridge City, East Cambridgeshire, Huntingdonshire, and South Cambridgeshire) which also incorporates the local subregional SATURN highway model (Atkins, 2015). The CSRM model is the successor of Cambridge's MEPLAN model, originally developed based on research conducted at The Martin Centre. Despite the model package being owned by Cambridgeshire County Council, one of our interviewees described the consultants' role in modeling processes as follows:

Technically the County Council owns the model, so they can take it back and they could give it to another company ... But the reality is the people who understand how to use it are all employed by 
Atkins ... I suspect there's a lot about the model which is not documented. It would just be the people who use it, know what that means, or how that works. So, the point I'm making, really, is the practicalities of transferring it to somebody else really mean Atkins has it in perpetuity (Interview 16, 2019).

Going forward, the Cambridgeshire and Peterborough Combined Authority set up a working group and allocated funding for a new Regional Transport Model to "assist with future investment within the Cambridgeshire and Peterborough region" which will replace the currently used CSRM package (Cambridgeshire and Peterborough Combined Authority, 2021).

Besides transport, data collection on air quality and associated modeling tasks are undertaken by Cambridge Environmental Research Consultants (a spinoff company of Cambridge University) in collaboration with Cambridge City Council, with some of the monitoring stations used to collect air quality data operated by consultants Ricardo Plc. Another consultancy, Steer, recently produced modeling studies for the Cambridgeshire Autonomous Metro (CAM) which was a strategic transport development coordinated by the Cambridge and Peterborough Combined Authority (CPCA) and the GCP (the development was since stopped by the new mayor of the Combined Authority). In addition, the GCP have commissioned further smaller-scale modeling exercises aligned with their programme and specific projects. Developers of strategic sites for spatial development are also required to produce transport impact assessments. One example of this privately commissioned modeling mentioned by our interviewees include Mott McDonald producing microsimulation models for the Cambridge railway station area. More recently, interest in data collection and modeling the regional energy systems also started to grow in conjunction with infrastructure developments such as charging stations for electric vehicles and increasing investment into local sustainable energy projects (Cambridgeshire County Council, 2020).

Rather than providing a comprehensive picture, this short overview aims to demonstrate how data and models have already become integral to decision-making in urban planning in Cambridge, despite the relative novelty of the smart city agenda. It also highlights the high level of reliance on external partners, typically consultants, to collect and process data, conduct modeling exercises and produce data-driven evidence for decision-making. Due to being provided externally as a service by private sector actors, the production of this data-driven knowledge remains largely detached from its use in decision-making. Some of our interviewees praised the efficiency of this arrangement, that is, the opportunity to draw on highly specialized expertise when needed. Many however also acknowledged that outsourcing led to a deterioration of in-house expertise within the local public sector with officers, senior managers and elected officials struggling to make sense of model results and recommendations. This in turn also translates into difficulties with contract commissioning and coordinating the work of consultants, posing further potential problems relating to the appropriateness and feasibility of policy recommendations based on data and modeling that do not consider top-down analogue political and practical implementation knowledges (cf. Head, 2008).

\subsection{Bottom-up and community-based knowledges}

Community-based knowledges have been found to emerge in both invited and invented spaces (Cornwall and Gaventa, 2001) in Cambridge. In invited spaces that form part of top-down policy processes, decision-making follows UK national directives of public consultation for local and regional governmental bodies (Cambridge City Council, 2019). Figure 1 shows the different consultation models and methods in use.

Beyond communicating strategic and operational decisions, various other top-down approaches are in use to facilitate citizen participation relating to the strategic vision for the city and the surrounding region as well as specific development or project schemes (see also Nochta et al., 2019c). The latter is usually conducted with a focus on place-based consultation involving residents and other citizens affected by these schemes. However, citizens and community groups are often dissatisfied with the participation opportunities that such invited spaces offer. They complain that consultations happen sporadically, spread 


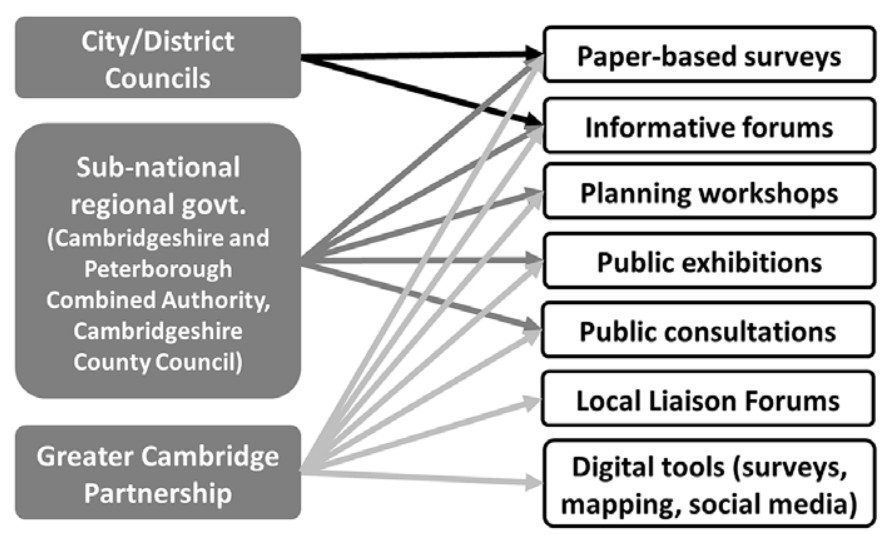

Figure 1. Consultation models and methods used by different local and regional government bodies in Cambridge.

over long time periods. In addition, the timing of engagement within the policy process remains contentious as citizens are often only consulted at more advanced stages of decision-making. As one of our respondents put it,

[I]f you want change, then you are always disadvantaged. Because the response is 'we've [local government] already got the plans.' But you didn't ask us before you got the plans... (Interview 8, 2019).

These perceived problems with traditional engagement models led community groups to take action and "invent" spaces for themselves in the policy sphere (Cornwall and Gaventa, 2001). These bottom-up approaches include various community groups with place-based (residents' associations) and issue-based (public transport, active travel) focus (Nochta et al., 2019c). Place-based residents' associations vary in size, main interests and activities but represent an increasingly strong voice in urban development and transport planning, including through the city-wide "Federation of Cambridge Residents' Associations" (FeCRA) that brings together the different neighborhood groups. The proliferation of residents' associations is (at least in part) facilitated by the adverse impacts of economic growth-driven spatial development agendas pursued by various powerful public sector bodies and lobby groups on local neighborhoods, communities and residents' everyday lives. Issue-based activist groups often have a focus on transport and mobility, and include for example Smarter Cambridge Transport, CamCycle, and Cambridge Connect. These groups have different core objectives, for example supporting cycling and active travel (CamCycle), road pricing and other traffic reduction schemes (Smarter Cambridge Transport), and regional light rail development (Cambridge Connect).

Similarly to FeCRA, Smarter Cambridge Transport has also become influential in the policy sphere due to their strong convening power across different (place-based and issue-based) community groups. They have been active participants in influential forums, regularly produce widely read responses to consultations, and effectively use news outlets and social media to build visibility and support, including a weekly column in one of the local newspapers that is popular with citizens and councilors (www. smartertransport.uk/category/cambridge-independent/). Smarter Cambridge Transport have also been active in developing bottom-up data-driven knowledges, drawing on their wide membership extending to professionals who possess the technical capabilities required for producing detailed data analysis. However, the scope of their work is often limited by the availability of open data relating to transport and mobility.

In addition to community groups, citizen participation in urban planning and development has also been driven by councilors (elected representatives) in some cases (Nochta et al., 2019c). A notable 
example is the local district councilor's efforts to involve an active professional and artist self-employed group (the "Neotists") in the steering committee for the Combined Authority's masterplan for the town (www.neotists.co.uk/projects/st-neots-masterplan/). In conjunction with the masterplan, the Neotists have also worked with the local council to improve community participation:

[A]s soon as a message is coming from an authority, then people are much less likely to listen to it. If that message is coming from their next-door neighbor, from somebody that they see as an advocate rather than somebody they have to pay their taxes to, their response is completely different. Although the [participatory event], it's basically a marketing exercise, ... it's paid for by the local authority, all the data is collected by the local authority and they're the ones that ultimately decide what happens to it. But the actual event is run by arts organisations which get the citizens' buy-in. If it was run as a government consultation, you'd get all the wrong people turning up, you'd get all the wrong people having these little bits of information. They would send you in all these directions, moaning about parking, or river levels or pollutions or there's too many pigeons, whatever it would be (Interview 12, 2019).

In recent years, the GCP have been particularly active in exploring new approaches to participation with the aim of including community voices and forming a "collective" of different stakeholders (Nochta et al., 2019c). An example of a new community engagement mechanism set up by the GCP are the socalled "Local Liaison Forums" (LLF). LLFs are intended to improve consultation with local residents on specific development schemes and projects. For example, an LLF has been set up in 2018 to further discuss current issues around the main road linking Cambridge and Haverhill, following an online survey. LLFs are chaired by local councilors and hold regular meetings (e.g., biannually; Milton Road Residents Association, 2018). Whilst the degree to which LLFs improved participatory processes remains debatable, increased interaction between the local authorities and residents has highlighted that limited or absent citizen inclusion at the design stage of proposed interventions can present great monetary and time costs for development projects.

One such case was the Milton Road Development which has been on the agenda since the 1980s. The proposed development involved the creation of new bus lanes on Milton Road, one of the main transport corridors leading into Cambridge city centre from the East. Due to ever-increasing congestion levels, partly as a result of the nearby "Science Park" (main employment site), the idea has been put on the table again and new plans were drawn up to ease congestion. However, local residents' groups (e.g., Milton Road Residents' Association, Hurst Park Estate Residents' Association) strongly opposed the new plans. They argued that local residents' interests were overlooked in the plans and criticized the reduction of green areas and tree coverage in the interest of bus and cycle lanes (www.miltonroadra.org/city-deal). The growing opposition forced the GCP to engage with the residents resulting in a lengthy consultation process through the LLFs. Despite the consultations being prolonged due to a series of internal personnel changes within the local authorities, ultimately many of the residents' demands were taken into consideration in the revised plans, especially in relation to conserving as much green space surrounding the road improvements as possible (www.miltonroadra.org/letters).

\subsection{Knowledge use: Impact on policy decision-making}

As the previous sections demonstrate, there are a variety of ways in which different types of data-driven and analogue knowledges are produced and influence strategic urban planning in the Cambridge city region. We found however that these different knowledges rarely interact, and rather than becoming elements of a multifaceted evidence-base for urban planning in Cambridge, they represent separate streams of evidence competing for influence over policy decision-making. This is despite the fact that the danger of relying overwhelmingly on "one-sided" evidence in policymaking has been recognized by many of our interviewees, including councilors, council officers as well as citizen activists and residents.

As an example, while many community group representatives welcome more data-informed policy, they also stress the importance of basing modeling exercises and decisions on data that is representative of 
the issues at hand (Nochta et al., 2021). They therefore call for better inclusion processes at the early stages of policy and strategy development in order to develop shared problem interpretations to improve the perceived legitimacy of data-driven knowledge production. Councilors and senior public sector officers also acknowledged that although the data-driven evidence affects the everyday lives of many, the opportunity to participate in how data collection and urban modeling processes are designed or used is limited (Smart Cambridge, 2020).

Exclusion is however not limited to community groups, as data-driven knowledge production typically follows the double-helix model in which consultants develop recommendations to deal with urban problems, with local governments perceived as their clients. Such dynamics often lead to a "black box" perception of data and models among officers and elected representatives. Decision-makers most often only see a ready-made interpretation of the results while data inputs, modeling assumptions and associated uncertainties are insufficiently understood (see also Nochta et al., 2019a). The double-helix arrangement, coupled with the lack of sufficient in-house expertise to make sense of data and quantitative analyses and suggest alternative options, may also reinforce path dependence in the spatial development solutions considered by decision-makers:

we're not using appraisal schemes as a decision-making tool. We're just using it as a way of reinforcing decisions that were made earlier. And what we're most lacking is an imaginative, reimagination of what the options should be. And because these things tend to be driven by engineers, the thing is put forward as an engineering solution and it sort of circularly supports the strategic objectives elsewhere. It becomes impossible to demonstrate that it's not the right thing to do (Interview 16, 2019).

At the same time, the potential benefits of combining data-driven and analogue knowledges to capture different kinds of important evidence for decision-making have been recognized by many of our interviewees. As one councilor described:

Sometimes we do our own surveys as well without the officers' support ... Most of our surveys are getting views and opinions, so they're qualitative, but occasionally do more statistical ones too ... For example, we wanted to look at a dangerous roundabout in my division ... We wanted to demonstrate the volume of the traffic and the different types, which is why we had to do the count ... I think it made our case much stronger because we were able to show how many vehicles there were every minute. And also, observations while we were doing that survey, you know, like cyclists getting off their bikes and crossing the road like a pedestrian, which shows people are frightened (Interview 11, 2019).

Our analysis also highlighted that participatory processes are key sites for the production of analogue community knowledges. However top-down participatory processes are not designed to negotiate spatial development targets and their delivery. Modeling exercises and the data collected for this purpose are not generally open toward citizens and communities, limiting options for public scrutiny and deliberating alternative plans in community settings. As such, complementary and contesting knowledges emerging from participatory processes often struggle to claim their place in the evidence-base for spatial development. Pieces of evidence, based on either data-driven or analogue knowledges, thus compete for influence over policy:

The GCP Board nodded through the plans for proceeding with busways. The communities in the west and south of Cambridge are gearing up to fight that at Public Enquiry. The Mayor of CPCA is backing the GCP. So, that sums up where things are (Interview 36, 2020).

Thus, while a type of hegemony of technological expertise emerges from processes of data-driven knowledge production, the rise of community action contesting the "digitization of everything," involving local community leaders, councilors and activists, remains an important contender to data-driven knowledges. An investigation into the interactions, or the lack thereof, between these two realms of 
knowledge reveals important political processes developing in response to top-down "smartification." Studying how such processes of competition, contestation, negotiation and complementarity arise from knowledge politics can help produce a more nuanced picture of to deepen our understanding of the diversity of ongoing smartification in different places (cf. de Hoop et al., 2018; Chang et al., 2021).

\section{Concluding Remarks: Avenues for Future Research into Knowledge Politics and Evidence in Smart City Governance}

This paper presented a knowledge politics perspective on evidence-informed decision-making in the context of smartification in cities. Informed by notions of "situatedness" and "positionality" we considered both data-driven and analogue knowledges as inherently partial, located and relational. This perspective highlights that despite its assumed objectivity, data-driven knowledges (as "scientific evidence") carry normative assumptions and values in their objectives, design, and implementation (Jasanoff, 2004). However, the case of strategic urban planning in Cambridge revealed that both datadriven as well as analogue knowledges are integral to the sociotechnical assemblage that governs smart city development. The ongoing smartification of cities will contribute to an abundance of data-driven knowledges and the advancement of "city science" (Batty, 2013). As such, finding ways to constructively combine diverse types and sources of knowledge to improve the evidence-base that informs policy decisions is a particularly pressing issue.

The Cambridge case reveals that interactions between data-driven and analogue knowledges can manifest in various political processes of competition, contestation, negotiation, and complementarity that are not necessarily consensus-seeking in nature. The analysis describes how competition for influence over policy fuels community activism in the city region. Claims and decisions made on the basis of datadriven knowledges derived from urban modeling are regularly contested by diverse activist and community groups. In order to strengthen such contestation processes, some community groups started to draw on contextualized expert competencies (e.g., based on their members) to develop bottom-up datadriven knowledges. As such, smartification becomes a cyclic process that does not automatically result in more sustainable and equitable cities, but instead may provide a means to move from a contested digitized present to negotiated "smart" city futures (cf. Nochta et al., 2019d). Negotiation however need not require the digitization of all community-based localized knowledge. Instead, both community groups and decision-makers seemed to acknowledge the potential complementarity of analogue knowledges that are informed by everyday lived experiences on the hyper-local neighborhood-level, and data-driven knowledge that can articulate the cascading effects of different spatial development options between different neighborhoods and localities.

Beyond demonstrating the potential benefits of employing a knowledge politics framework to develop a more nuanced understanding of local smart city development trajectories, our research also highlighted several gaps that future research could address. All of these gaps relate to our key objective: developing and maintaining mechanisms that result in "multifaceted" evidence-bases drawing on diverse analogue and data-driven knowledges.

First, the discussion presented in this paper focused on analogue knowledges that emerge from community settings from the bottom up. We mentioned only tangentially that a variety of other types of analogue knowledges are likely to exist, such as Head's (2008) political and practical implementation type knowledges, as well as different professional expertise and so on. As such, future research is required to better understand what other "analogue" knowledges might be relevant to smartification; whether these contribute to reinforcing or contesting a hegemonic practice of top-down data-driven knowledge production; and potentially cause policymakers to be less receptive to emerging bottom-up data-driven knowledges, excluding these from the evidence-base for policy.

Second, our study indicated that although "communities" are often interpreted in spatial terms in the context of smartification and urban planning, such as neighborhoods, communities also form around particular issues such as promoting cycling, or based on particular backgrounds such as artist and freelancer groups. Future research could therefore investigate the similarities and differences among 
different groups, and their interactions and networks. This research could be particularly useful for providing a more robust knowledge production perspective to improve participatory processes, for example in terms of their reach or representativeness, and deal with potential NIMBY-ism and/or elite capture. It could also contribute to designing participatory processes that allow diverse people and perspectives to mix and new knowledges to emerge (cf. de Hoop et al., 2018), as well as digital tools that can support such knowledge production (cf. Smith and Martín, 2021).

Third, in our case top-down data-driven knowledge production was mainly motivated by economic growth targets, and driven as much by the local public sector, central government mandates and funding schemes, as much as by corporate interests. In a similar vein, Chang et al.'s (2021) analysis highlights the mobilization of the smart city agenda as a political strategy to facilitate urban regime transition in Taipei. This indicates that smartification and data-driven knowledge production processes may be in the service of different local goals in different places - in contrast to the mainstream view of corporate-led smart city development. Consequently, the local politics of knowledge production may encompass different dynamics and processes compared to what is described in this paper. Building a deeper understanding of what kinds of analogue and data-driven knowledges are produced and used in different cities and how, and their impact on local smartification trajectories, could contribute to developing a more nuanced interpretation of smartification in different places.

Acknowledgments. The authors are grateful for the support of local authority partners in Cambridge, in particular Daniel Clarke and Gemma Schroeder of the Smart Cambridge team. The authors are also grateful to colleagues Dr Li Wan, Dr Junqing Tang, and Nicole E. Badstuber for their support and insights on earlier versions of this paper.

Funding Statement. The authors are thankful for the financial support received from the Centre for Digital Built Britain, under Innovate UK grant number RG96233. The study is part of the Digital Cities for Change Programme funded by The Ove Arup Foundation (RG89525). The Cambridge Centre for Smart Infrastructure and Construction is funded by Innovate UK and EPSRC (EP/N021614/1, EP/I019308/1, and EP/K000314/1). None of the funders had any role in study design, data collection and analysis, decision to publish, or preparation of the manuscript.

Competing Interests. The authors declare no competing interests exist.

Author Contributions. Conceptualization: T.N., N.W.; Data curation: T.N., N.W.; Formal analysis: T.N., N.W.; Funding acquisition: T.N., J.M.S.; Investigation: T.N., N.W.; Methodology: T.N., N.W.; Project administration: T.N.; Supervision: T.N., J.M.S.; Writing—original draft: T.N., N.W.; Writing—review and editing: T.N., J.M.S.

Data Availability Statement. Data availability is not applicable to this article as no new data were created or analyzed in this study.

\section{References}

Atkins (2015) CSRM Technical Modelling Report for Cambridge and South Cambridgeshire Local Plans. Supplementary Technical Note, November 2015. Available at https:/files.cambridge.gov.uk/public/ldf/coredocs/rd-mc-071.pdf (accessed 22 September 2021).

Batty M (2013) The New Science of Cities. Cambridge, MA: MIT Press.

Bhan G (2016) Asking the wrong question: Smart cities in contemporary urban India. In Beware of Smart People! Redefining the Smart City Paradigm towards Inclusive Urbanism: Proceedings of the 2015 “Beware of Smart People!" Symposium. Berlin: Universitätsverlag der TU Berlin, pp. 103-106.

Björkman L and Harris A (2018) Engineering cities: Mediating materialities, infrastructural imaginaries and shifting regimes of urban expertise. International Journal of Urban and Regional Research 42(2), 244-262.

Cairney P (2016) The Politics of Evidence-Based Policy Making. Cham: Springer.

Cambridge City Council (2019) Consultations | Cambridge City Council. Available at www.cambridge.gov.uk/Consultations (accessed 2 May 2021).

Cambridgeshire and Peterborough Combined Authority (2021) New Regional Model to Signpost Transport Projects across Cambridgeshire and Peterborough Receives Approval. Available at https://cambridgeshirepeterborough-ca.gov.uk/news/newregional-model-to-signpost-transport-projects-across-cambridgeshire-and-peterborough-receives-approval/ (accessed 22 September 2021).

Cambridgeshire and Peterborough Independent Economic Commission (2018) Final Report. The Cambridgeshire and Peterborough Independent Economic Review. Available at www.cpier.org.uk/final-report/ (accessed 2 May 2021). 
Cambridgeshire County Council (2020) Overcoming Barriers to Delivery of Renewable Energy - Low Carbon Future for Cambridgeshire. Available at https://www.cambridgeshire.gov.uk/residents/climate-change-energy-and-environment/climatechange-action/low-carbon-energy (accessed 2 May 2021).

Chang ICC, Jou SC and Chung MK (2021) Provincialising smart urbanism in Taipei: The smart city as a strategy for urban regime transition. Urban Studies 58(3), 559-580.

Cornwall A and Gaventa J (2001) Bridging the gap: Citizenship, participation and accountability. PLA Notes 40(2001), 32-35.

de Hoop E, Smith A, Boon W, Macrorie R, Marvin S and Raven R (2018) Smart urbanism in Barcelona: A knowledge-politics perspective. In Jensen JS, Cashmore M and Späth PR (eds), In the Politics of Urban Sustainability Transitions: Knowledge, Power and Governance. London: Routledge.

Du M, Zhang X and Mora L (2021) Strategic planning for smart city development: Assessing spatial inequalities in the basic service provision of metropolitan cities. Journal of Urban Technology 28(1-2), 115-134.

Echenique M (2005) Forecasting the sustainability of alternative plans, the Cambridge futures experience. In Future Forms and Design for Sustainable Cities. London: Routledge, pp. 113-133.

Gabrys J (2014) Programming environments: Environmentality and citizen sensing in the smart city. Environment and Planning D: Society and Space 32(1), 30-48.

Gopakumar G (2020) Regime of congestion: Technopolitics of mobility and inequality in Bengaluru, India. Science as Culture $29(3), 345-364$.

Haraway D (1988) Situated knowledges: The science question in feminism and the privilege of partial perspective. Feminist Studies 14(3), 575-599.

Head BW (2008) Three lenses of evidence-based policy. Australian Journal of Public Administration 67(1), 1-11.

Head BW (2010) Reconsidering evidence-based policy: Key issues and challenges. Policy and Society 29(2), 77-94. http:// dx.doi.org/10.1016/j.polsoc.2010.03.001

Hunt JD, Kriger DS and Miller EJ (2005) Current operational urban land-use-transport modelling frameworks: A review. Transport Reviews 25(3), 329-376.

Interview 8 (2019) Representative of Cambridge Neighbourhood Residents' Association. Interview with N. Wahby on 26/03/2019. Cambridge.

Interview 11 (2019) Councilor at Cambridgeshire County Council. Interview with N. Wahby on 02/04/2019. Cambridge.

Interview 12 (2019) Representative of Community Professional Group. Interview with N. Wahby on 04/04/2019. Cambridge.

Interview 16 (2019) Representative of Community Campaign Group. Interview with N. E. Badstuber on 12/04/2019. Cambridge.

Interview 36 (2020) Representative of Community Campaign Group. Post-Interview Email Exchange. Interview with T. Nochta on 30/04/2020. Cambridge.

Jacobs N, Edwards P, Markovic M, Cottrill CD and Salt K (2020) Who trusts in the smart city? Transparency, governance, and the internet of things. Data \& Policy 2, E11.

Jasanoff S (ed.) (2004) States of Knowledge: The Co-Production of Science and the Social Order. London: Routledge.

Jin Y (forthcoming) Introduction. In British Academy Proceedings on Applied Urban Modelling. Oxford: Oxford University Press.

Karvonen A (2020) Urban techno-politics: Knowing, governing, and imagining the city. Science as Culture 29(3), 417-424.

Khan HH, Malik MN, Zafar R, Goni FA, Chofreh AG, Klemeš JJ and Alotaibi Y (2020) Challenges for sustainable smart city development: A conceptual framework. Sustainable Development 28(5), 1507-1518.

Kitchin R (2014) The real-time city? Big data and smart urbanism. GeoJournal 79(1), 1-14.

Kitchin R (2016) The ethics of smart cities and urban science. Philosophical Transactions of the Royal Society A: Mathematical, Physical and Engineering Sciences 374(2083), 20160115.

Leszczynski A (2016) Speculative futures: Cities, data, and governance beyond smart urbanism. Environment and Planning A: Economy and Space 48(9), 1691-1708.

Leino, H. and Peltomaa, J., 2012. Situated knowledge-situated legitimacy: Consequences of citizen participation in local environmental governance. Policy and Society, 31(2), pp.159-168.

Mancebo F (2020) Smart city strategies: Time to involve people. Comparing Amsterdam, Barcelona and Paris. Journal of Urbanism: International Research on Placemaking and Urban Sustainability 13(2), 133-152.

Marvin S and Luque-Ayala A (2017) Urban operating systems: Diagramming the city. International Journal of Urban and Regional Research 41(1), 84-103.

Meijer A and Bolívar MPR (2016) Governing the smart city: A review of the literature on smart urban governance. International Review of Administrative Sciences 82(2), 392-408.

Merrifield A (1995) Situated knowledge through exploration: Reflections on Bunge's 'geographical expeditions'. Antipode 27(1), 49-70.

Milton Road Residents Association (2018) Notes from the Milton LLF October 2018. Available at www.miltonroadra.org/news/ categories/city-deal (accessed 2 May 2021).

Mora L, Deakin M and Reid A (2019) Strategic principles for smart city development: A multiple case study analysis of European best practices. Technological Forecasting and Social Change 142, 70-97.

Mora L, Deakin M, Zhang X, Batty M, de Jong M, Santi P and Appio FP (2021) Assembling sustainable smart city transitions: An interdisciplinary theoretical perspective. Journal of Urban Technology 28(1-2), 1-27. 
Nochta T, Badstuber N and Wahby N (2019a) On the Governance of City Digital Twins-Insights from the Cambridge Case Study. CDBB Working Papers 12. Centre for Digital Built Britain. Available at www.repository.cam.ac.uk/handle/1810/293984 (accessed 2 May 2021).

Nochta T, Badstuber NE and Wan L (2019b) Evidence-Informed Decisionmaking in Multi-stakeholder Settings: The Case of City Digital Twins for Planning and Management. Data for Policy. Available at https://zenodo.org/record/2798858\#.XNr0SqTTVPZ (accessed 2 May 2021).

Nochta T, Parlikad A, Schooling J, Badstuber N and Wahby N (2019c) The Local Governance of Digital TechnologyImplications for the City-Scale Digital Twin. Final Report. Centre for Digital Built Britain. Available at www.repository.cam.ac.uk/handle/1810/296276 (accessed 2 May 2021).

Nochta T, Wan L, Schooling JM, Lemanski C, Parlikad AK and Jin Y (2019d) Digitalisation for smarter cities: Moving from a static to a dynamic view. Proceedings of the Institution of Civil Engineers-Smart Infrastructure and Construction 171(4), $117-130$.

Nochta T, Wan L, Schooling JM and Parlikad AK(2021) A socio-technical perspective on urban analytics: The case of city-scale digital twins. Journal of Urban Technology 28(1-2), 263-287.

Panori A, Kakderi C, Komninos N, Fellnhofer K, Reid A and Mora L (2020) Smart systems of innovation for smart places: Challenges in deploying digital platforms for co-creation and data-intelligence. Land Use Policy, 104631.

Parkhurst J (2017) The Politics of Evidence: From Evidence-Based Policy to the Good Governance of Evidence. London: Taylor \& Francis, p. 182.

Pollitt C and Bouckaert G (2011) Public Management Reform: A Comparative Analysis - New Public Management, Governance, and the Neo-Weberian State, 3rd Edn. Oxford: Oxford University Press.

Rose G (1997) Situating knowledges: Positionality, reflexivities and other tactics. Progress in Human Geography 21(3), 305-320.

Smart Cambridge (2020) Stakeholder Engagement Report. Biomedical Campus City Digital Twin Experiment. Cambridgeshire County Council. Available at www.connectingcambridgeshire.co.uk/wp-content/uploads/2020/10/CBC-City-Digital-TwinExperiment.pdf (accessed 2 May 2021).

Smith A and Martín PP (2021) Going beyond the smart city? Implementing technopolitical platforms for urban democracy in Madrid and Barcelona. Journal of Urban Technology 28(1-2), 311-330.

Söderström O, Paasche T and Klauser F (2014) Smart cities as corporate storytelling. City 18(3), 307-320.

Turnpenny JR, Jordan AJ, Benson D and Rayner T (2015) The tools of policy formulation: An introduction. In The Tools of Policy Formulation. Cheltenham: Edward Elgar.

van Winden W and van den Buuse D (2017) Smart city pilot projects: Exploring the dimensions and conditions of scaling up. Journal of Urban Technology 24(4), 51-72.

Wan L, Tang J, Wang $\mathbf{L}$ and Schooling $\mathbf{J}$ (2021) Understanding non-commuting travel demand of car commuters-insights from ANPR trip chain data in Cambridge. Transport Policy 106, 76-87.

Wastell DG (2006) Information systems and evidence-based policy in multi-agency networks: The micro-politics of situated innovation. The Journal of Strategic Information Systems 15(3), 197-217.

Wilson AG (1998) Land-use/transport interaction models: Past and future. Journal of Transport Economics and Policy 32, 3-26.

Zandbergen D and Uitermark $\mathbf{J}$ (2020) In search of the smart citizen: Republican and cybernetic citizenship in the smart city. Urban Studies 57(8), 1733-1748.

Zuzul TW (2019) "Matter battles": Cognitive representations, boundary objects, and the failure of collaboration in two smart cities. Academy of Management Journal 62(3), 739-764.

Cite this article: Nochta T, Wahby $\mathbf{N}$ and Schooling J. M (2021). Knowledge politics in the smart city: A case study of strategic urban planning in Cambridge, UK. Data \& Policy, 3: e31. doi:10.1017/dap.2021.28 